Published in final edited form as:

Soc Sci Med. 2015 May ; 133: 205-211. doi:10.1016/j.socscimed.2015.03.004.

\title{
Diet and Obesity in Los Angeles County 2007-2012: Is there a measurable effect of the 2008 "Fast-Food Ban"?
}

\author{
Roland Sturm, Ph.D. and \\ RAND Corporation
}

\author{
Aiko Hattori, Ph.D. \\ Carolina Population Center, University of North Carolina at Chapel Hill
}

\begin{abstract}
We evaluate the impact of "Los Angeles Fast-Food Ban", a zoning regulation that restricts opening/remodeling of standalone fast-food restaurants in South Los Angeles since 2008. Food retail permits issued after the ban are more often for small food/convenience stores and less often for larger restaurants not part of a chain in South Los Angeles compared to other areas; there are no significant differences in the share of new fast-food chain outlets, other chain restaurants, or large food markets. About $10 \%$ of food outlets are new since the regulation, but there is little evidence that the composition has changed differentially across areas. Data from the California Health Interview Survey show that fast-food consumption and overweight/obesity rates have increased from 2007 to 2011/2012 in all areas. The increase in the combined prevalence of overweight and obesity since the ban has been significantly larger in South Los Angeles than elsewhere. A positive development has been a drop in soft drink consumption since 2007, but that drop is of similar magnitude in all areas.
\end{abstract}

\section{Keywords}

Food environment; Fast food; Overweight/obesity; Diet; Los Angeles County, California

\section{INTRODUCTION}

The obesity epidemic has spawned many attempts to change diets and increased the profile of non-medical approaches to prevention in health policy debates. In the U.S., policy initiatives to change food environments and availability of nutritionally less desirable foods have rarely succeeded politically or legally, the exception being policies limited to public schools. New York City's regulation to limit the serving size of caloric soft drinks to no more than 16 ounces was struck down the day before it became effective. None of many

\footnotetext{
(C) 2015 Published by Elsevier Ltd.

Corresponding author: Aiko Hattori, Ph.D., MEASURE Evaluation, 400 Meadowmont Village Circle, 3rd Floor, Chapel Hill, NC 27517, Phone: (919) 445-0448, Fax: (919) 445-9353, hattori@ email.unc.edu.

Publisher's Disclaimer: This is a PDF file of an unedited manuscript that has been accepted for publication. As a service to our customers we are providing this early version of the manuscript. The manuscript will undergo copyediting, typesetting, and review of the resulting proof before it is published in its final citable form. Please note that during the production process errors may be discovered which could affect the content, and all legal disclaimers that apply to the journal pertain.
} 
proposals to levy new taxes on soft drinks or other types of junk food has been adopted in the U.S. However, such taxes have been implemented in other countries with health goals. The most recent country is Mexico, which added a 1 peso per liter tax on sugared beverages and an 8 percent tax on calorie dense snack foods starting January 2014, corresponding to $10 \%$ price increase for a 2 liter drink.

The "Los Angeles Fast-Food Ban" is a rare exception in the U.S. and received international attention when passed in 2008. It is a unique policy that deserves an evaluation now that several years have passed. The Los Angeles Fast-Food Ban was introduced as a draft ordinance in the Los Angeles City Council in 2007 and after an extended debate was passed unanimously in July 2008.(Office of the City Clerk, City of Los Angeles, 2008) It became effective on September 14, 2008, initially as a temporary ordinance, but the City Council made it a permanent amendment to the city's General Plan in December 2010.(Office of the City Clerk, City of Los Angeles, 2010) Despite its nickname, the policy is a zoning regulation that restricts opening or expanding a "stand-alone fast-food restaurant" in Baldwin Hills, Leimert Park, and portions of South Los Angeles and Southeast Los Angeles; the paper refers to this area as South Los Angeles. Fast-food restaurants are defined as "any establishment which dispenses food for consumption on or off the premises, and which has the following characteristics: a limited menu, items prepared in advance or prepared or heated quickly, no table orders, and food served in disposable wrapping or containers." (Office of the City Clerk, City of Los Angeles, 2010, pF-1) The regulation prevents new drive-through windows, new stand-alone fast food restaurants, or expanding floor space. It does not affect interior remodeling or exterior changes that do not increase the floor space. For example, a fast food restaurant that shares a building in a strip mall would not be subject to the regulation. The area subject to the rule has about 700,000 residents, which by itself would make it one of the 20 largest cities in the U.S.(City of Los Angeles) The councilmembers who introduced the measure argued that the proliferation of fast-food outlets in their district "..creates serious public health problems through poor nutrition for children."(Office of the City Clerk, City of Los Angeles, 2008, p1) While the Los Angeles Fast-Food Ban was not the first local regulation limiting fast-food outlets (a few small tourist locations implemented similar rules, but for aesthetic reasons), it was the first regulation presented by its proponents as a health measure and for a major area.

The rationale for the Fast-Food Ban put forward by its proponents parallels influential health policy statements, including the White House Task Force on Childhood Obesity, which attributes poor diets and high obesity rates in low-income neighborhoods to a lack of "convenient access to affordable and healthy food. Instead of supermarkets or grocery stores, these communities often have an abundance of fast-food restaurants and convenience stores."(White House Task Force on Childhood Obesity, 2010, p49) Research has documented disparities in food availability and some studies argue that neighborhood food environments causally affect diets. (Larson, et al., 2009) This provides a plausible mechanism of how the regulation could affect food consumption and possibly even obesity rates.

This paper analyzes whether the composition of new food outlets since the regulation differs between South Los Angeles and either the remainder of the city of Los Angeles or Los 
Angeles County and whether there are differential changes in diet behaviors and obesity over time. We analyze the first issue with the Los Angeles County Department of Public Health's database of food retail permits and the second with 2007-2012 cross-sectional surveys from the California Health Interview Survey.

\section{MATERIALS AND METHODS}

\section{Food Environments}

The Los Angeles County Department of Public Health issues food permits and inspects all licensed food outlets. (County of Los Angeles) The Department provided their permit/license database as of February 2013 in excel; duplicate permits and permits for food outlets under military veteran organizations were removed. The database collects addresses, issue date, permit types (restaurant, retail food market), and size. We analyze the type of permits issued after the Fast-Food Ban regulation became effective on September 14, 2008.

We distinguish 6 types of food permits:

1. Fast-food chains with 10 or more outlets in Los Angeles (these are the type of restaurants most likely to be subject to the regulation)

2. Other restaurant chains with 10 or more outlets (not fast-food and usually not satisfying some of the criteria about menu and food preparation)

3. Individual or small chain restaurants with seating up to 10 people

4. Individual or small chain restaurants with seating for more than 10 people

5. Small food stores (under $2,000 \mathrm{sqft}$ )

6. Large food stores (over $2,000 \mathrm{sqft}$ ).

We used name searches to identify chains with 10 or more locations in Los Angeles County and manually classified them as "fast-food" if they predominantly serve hamburgers, pizza, tacos, sandwiches, fried chicken, etc. Restaurants in this group tend to satisfy the criteria of the regulation about stand-alone and limited menus, but not all do. Subway restaurants, for example, tend to be in shared buildings, not stand-alone restaurants, nor do they have drivethrough service.

About $30 \%$ of outlets belonging to chains that have more than 10 outlets do not fit into a "fast-food group" and we group them into "other chain restaurants". This is a mixed group, including full-service restaurants (Denny's is the biggest with 88 outlets in Los Angeles County), coffee shops (Starbucks is the biggest in that category with 350 outlets), ice cream parlors (Baskin Robbins is the biggest with 116 outlets), but shares the feature that they would be unlikely to be affected by the fast-food ban. We separated the remaining restaurants by size (10 or fewer seats or more than 10 seats). A large number of the small restaurants (10 or fewer seats) sell baked goods, donuts, ice cream. Many are taco stands and we expect that the majority sells some type of "fast food", but they would not satisfy the criterion of the regulation of being a "stand-alone fast-food restaurant". The small stores are predominantly mini-marts, convenience stores (whether just food stores or part of a gas 
station) with a small set of specialty stores (e.g. meat markets). We use a two-sample test for proportions for a particular category between areas.

\section{Diet and Obesity}

Diet and obesity measures come from the 2007, 2009, and 2011-2012 waves of the California Health Interview Survey (CHIS), a random-digit-dial telephone survey of California's non-institutionalized population.(UCLA Center for Health Policy Research) We use the restricted files that identify a survey respondent's residential address. In the three waves, a total of 141,597 adults ages 18 years and older were interviewed. The sampling weights provided by CHIS account for unequal sampling probabilities and non-response. We exclude pregnant women $(0.5 \%)$, respondents whose information was provided through a proxy interview $(0.5 \%)$, and residents of areas defined as rural $(1.7 \%)$.

The diet measures are the number of times per week the following items were consumed: fast-food, soft drinks (excluding diet), fruits (excluding juices), and vegetables (excluding fried potatoes). Body mass index (BMI) was calculated from self-reported height and weight and we classify respondents into "overweight or obese" (BMI 225.0 ) and "obese" (BMI $\geq$ 30.0), according to World Health Organization classifications for adults.(World Health Organization)

The intervention group is respondents living in South Los Angeles, that is, the area targeted by the Fast-Food Ban ( $n=467$ in 2007, 483 in 2009, and 535 in 2011-2012). The comparison groups are either respondents living in other parts of the city of Los Angeles ( $n=3,829$ in 2007, 2,920 in 2009, and 3,034 in 2011-2012) or living in other parts of Los Angeles County ( $\mathrm{n}=11,591$ in 2007, 8,377 in 2009, and 8,252 in 2011-2012). We assess crosssectional differences between areas and difference-in-differences (DID, whether secular changes in diet or obesity in South Los Angeles differ from secular changes in other areas).

Our main statistical analysis uses regression analysis to address potentially confounding variables at the individual and neighborhood level (including socio-demographic changes that may differ across areas): gender, age, race/ethnicity, household size, annual household income, education, and marital status at the individual level; population density, median household income, and proportion of non-Hispanic Whites of residential census tract from the 2010 Census as neighborhood-level covariates. In the regression, we include data from the intermediate 2009 wave and results are based on 1,485 respondents in South Los Angeles, 28,220 respondents residing in other areas of Los Angeles County, and 9,783 respondents residing in Los Angeles City but outside the intervention area.

Ordinary Least-Squares regression is used for a continuous outcome variable (BMI), negative binomial regression for count variables (dietary intake frequencies), and logistic regression for dichotomous variables (overweight and obese status). We weight the regression using sampling weights provided in the data and use Eicker-Huber-White sandwich estimator to obtain heteroscedasticity-robust standard errors. The main coefficient of interest in the regression is the interaction between time since the regulation and area, but because it is hard to interpret except for OLS, we instead show the test statistics (either z- or $\mathrm{t}$-values) as a test of significance. 


\section{Limitations}

Measuring restaurants type over time is generally difficult as historic data are unavailable and commercial business listings like InfoUSA or Dunn and Bradstreet have limited accuracy. (A. D. Liese, et al., 2013; A. D. Liese, et al., 2010; Powell, et al., 2011). The LA County food licensing data, which is used for on-the-ground inspections, has good accuracy and captures time, but the database has its own idiosyncratic limitations. While it maintains historic license data, if a food outlet at a specific location changes ownership, only the latest owner is in the database. Our results therefore focus on the composition of new licenses and their share to total outlets. There is no database that would classify classify restaurants by type of food. Instead, we identified chains by names and classified them.

For the individual-level analysis, the biggest limitation is in sample sizes. While CHIS is the largest data set available to capture smaller geographic distinction, there are only around 500 observations per wave among residents in South LA. The sample size constrains the effect sizes that are detectable with good statistical power. The standard error for several key variables (frequency of fast-food, obesity, soft drinks) is about $1 / 10$ of the mean, although combining waves and multiple regression increases precision.

Diet questions of CHIS are limited; they probe for a small number of items, do not provide guidance on serving size, and have a recall period of one month (except for the fast-food consumption, which had a recall period of one week). The BMI measures are based on selfreported height/weight, which tend to be lower than objectively measured BMI,(Gorber \& Tremblay, 2009; Merrill \& Richardson, 2009; Stommel \& Schoenborn, 2009) although it allows comparisons over time.(Gorber \& Tremblay, 2009)

\section{RESULTS}

\section{New Food Outlets Since the Regulation}

We show two comparisons. The first comparison in Figure 1 shows how the composition of new food retail outlets (new food licenses issued by the Department of Public Health since the regulation) differs between South Los Angeles, other parts of the city of Los Angeles, and other parts of Los Angeles County. There are two major differences between South Los Angeles and other areas: In South LA, a new retail opening is most likely to be for a small food store, whereas in other areas, it is most likely for a larger independent restaurant. Using pairwise tests of proportions, these two categories show a highly statistically significant difference, while other categories are more similar and not statistically different. In particular, that means that the share of new restaurants belonging to a fast-food chain or of large grocery stores or of small restaurants are similar across areas. There were 17 new permits for outlets belonging to larger fast-food chains in South Los Angeles, and the share is slightly larger compared to the other areas (while not statistically significant). We checked them individually using images obtained from Google Street View, and none of them were stand-alone restaurants.

The second comparison (Figure 2) presents the share of new food retail outlets relative to all operating outlets in that category as of February 2013. About 10\% of the food outlets operating in Los Angeles County as of February 2013 received a food retail permit after the 
Fast-Food Ban regulation became effective on September 14, 2008. In all areas, the largest share of new relative to all operating outlets is for small restaurants, which is expected as small restaurants are also very likely to fail and go out of operation (the database do not allow classification of closed outlets). The shares differ slightly between areas, but there are no significant differences between South LA and other areas based on a chi-square test stratified by food outlet category. That suggests that the food environment is not changing differentially but rather that the composition of new retail outlets in Figure 1 mirrors the existing food environment.

\section{Diet and Obesity}

Table 1 shows weighted descriptive statistics for diet and body composition measures using the 2007 (pre-regulation) and the 2011-2012 (post-regulation) waves of the California Health Interview Survey. Before the regulation, as well as 3-4 years later, average BMI, obesity prevalence, and overweight/obese prevalence were higher in South Los Angeles than in other areas. Over time, average BMI and prevalence rates have increased in all areas. Moreover, the gap between South Los Angeles and other areas has widened, not narrowed. The last two columns show the results for a difference-in-differences analysis. A positive value indicates a larger increase from 2007 to 2011/12 in South Los Angeles than the increase from 2007 to 2011/12 in the comparison areas, which is true for all 3 measures and statistically significant for the combined overweight/obese category.

The second part of the panel shows the corresponding values for dietary measures. Fast-food and soft drink consumption is significantly higher in South Los Angeles (except for fastfood consumption in the 2007 wave in comparison with the other parts of Los Angeles County) and vegetable consumption significantly lower (except for in the 2007 wave in comparison with the other parts of Los Angeles County), with no major differences for fruit (except for in the 2007 wave in comparison with the other parts of Los Angeles City). Over time, fast-food consumption increased in all areas and the DID point estimate is again positive, indicating a larger increase in fast-food consumption in South Los Angeles over time than elsewhere, rather than a drop in consumption in South Los Angeles or at least a narrowing of the gap. However, that point estimate is small and statistically not significant, so it should be interpreted more as similar increases in all areas.

A positive development is the drop in soda consumption in all areas and the DID point estimate is even negative, indicating a larger drop in South Los Angeles and therefore a narrowing gap over time. But since it is statistically insignificant, we should interpret this as a drop in soda consumption that is similar in all areas. There are no significant DID estimates for fruit and vegetables and the sign is in the opposite direction.

\section{Multiple Regression Results for Diet and Obesity}

Table 2 presents the results of multiple regression analogous to DID approach, estimated through the interaction between survey year and the indicator of intervention group, on the dietary intake frequencies and BMI measures, using the combined data of the 2007-2011 waves and controlling for the covariates. Only the estimated regulation impact on the combined overweight/obese category was statistically significant, and the positive value of 
the point estimate suggests a widening gap over time. This is the opposite direction of the intended effect of the regulation. None of the other estimated regulation impacts were statistically significant, either for dietary intake frequencies (fast-food, sugar-sweetened soft drinks, fruits, and vegetables) or other BMI measures (BMI and a BMI 230 ). Moreover, the point estimates (while not statistically significant) show a larger increase of fast-food consumption among people living in the area targeted by the regulation.

\section{DISCUSSION}

Despite a vigorous debate of policy interventions to change food environments, very few identifiable policies have been implemented. The Los Angeles Fast-Food Ban was hailed by advocates (and castigated by opponents) as a landmark policy to change food environments when it became effective in 2008 and received international attention. This is the first study to examine the effect of the regulation in changing food environments, dietary intake, and weight status among residents.

Analyzing new food licenses issued by the Los Angeles County Department of Health, we found that environmental change is slow: About $10 \%$ of food outlets in South LA operating at the beginning of 2013 opened after the 2008 regulation, roughly similar in all areas, which corresponds to an annual rate of slightly over $2 \%$. That means that policies should not be expected to have a substantial impact in the short-run, although it could contribute to dietary changes over a longer horizon. We also found that the rate of new fast food chain restaurants is no different in South LA than other areas of LA, mainly because the new fast food restaurants in South LA were not "free-standing", but in shared space. When comparing the share of new food retail permits, the main difference is that the largest group in South LA are small food stores, whereas in other areas it is larger restaurants. Among the 190 new licenses in South Los Angeles, 86 (45\%) are for food stores under 2,000 sqft, twice the share of other areas. Outside South LA, larger independent restaurants account for the largest share of new licenses. We classify the type of food, but there is little reason to believe that sit-down restaurants are any more conducive to healthy diets than fast food restaurants: Main entrées in family-style restaurants have significantly more energy, fat and saturated fat than in fast-food restaurants. (Wu \& Sturm, 2013)

Given the slow environmental change (about $2 \%$ of outlets change each year) and similar rates of new fast-food chain restaurants in all areas, we do not believe that changes in the food environment due to the regulation could have had a meaningful impact on dietary choices in South LA. It does not preclude the possibility that diets and obesity rates have changed for other reasons. Changes in local food environment are neither necessary nor sufficient for changes in diets and obesity and policies may impact health outcomes through other ways. The South Los Angeles Fast-Food Ban may have a symbolic value, changing community norms and attitudes about diets. This may in the long run accelerate business transformation and so a policy may achieve its goal more indirectly and through other pathways. Policies may also be a consequence - rather than a cause - of changing preferences. 
Advocates have claimed dramatic improvements in health since the adoption of the regulation: A 3 percentage point drop in obesity rates and a 2 percentage point drop in diabetes rates in South Los Angeles.(Community Health Councils, 2013) The evidence for those claims is unclear, but such outcomes would require very large changes in diets. We therefore also investigated whether there are measurable differential changes in diets over time between residents in South LA versus other areas.

The analysis of the California Health Interview Survey does not show the large improvements in obesity or diet in South Los Angeles following the Fast-Food Ban that would be needed to reduce obesity and diabetes rates or reduce disparities. Obesity and overweight rates continue to increase in all study areas and the combined prevalence of overweight/obesity has increased significantly faster in South Los Angeles than elsewhere since the regulation. Overall, fast-food consumption appears to have increased as well, although there is no significant difference in the change between areas. One bright spot might be a decline in soft drink consumption, but as with fast food consumption, there is no differential change over time across areas.

While the absence of substantial differential changes in South LA stands in sharp contrast to the heated policy debate surrounding the regulation, it should not come as a surprise. First, the target of the regulation (stand-alone fast-food restaurants) was unlikely to be an effective way to address disparities in the food environment or diets: Prior to the regulation, South Los Angeles had more small retail stores, but not more (if anything fewer) large fast-food restaurants than wealthier areas of Los Angeles per capita.(Sturm \& Cohen, 2009) Consistent with the business structure, residents in South LA also had a higher consumption of discretionary calories from candy, cookies, and soda.(Sturm \& Cohen, 2009) This pattern has simply continued in new food retail permits since the regulation: Very small food stores account for about $45 \%$ of new food outlets in South LA since 2008, but for less than $25 \%$ in other areas.

There is a widespread belief that low-income or minority neighborhoods have an overconcentration of fast food chains. This belief was enshrined in the justification for the interim regulation that stated: “..whereas there is an overconcentration of fast food restaurants in the South Los Angeles region, as shown in recent reports including a Los Angeles Times report (September 2007) which found that $45 \%$ of the 900 restaurants in South LA are fast-food outlets with minimal seating, compared with $16 \%$ of 2,200 restaurants in the west side of the city." (Office of the City Clerk, City of Los Angeles, 2008) Yet the original calculation counted any restaurants with seating for less than 10 as fast-food, regardless of the type of food produced. Virtually none of those small restaurants are affected by the regulation, which focuses on free-standing buildings with surface parking, multiple driveways, and drive-through windows. There was a complete disconnect between the justification and the policy. At that time of the regulation, there were actually fewer fast food chain restaurants (the type likely to be affected by the regulation) in South LA than elsewhere on a per capita basis (Sturm and Cohen, 2009). Instead, South LA had relative more small independent restaurants with limited seating. The majority is likely to offer some type of "fast food", but that is probably true for restaurants with more seating as well. 
There is another reason why targeting free-standing fast food restaurants may not lead to changes in the diets of residents. Free-standing fast food restaurants tend to be located on major roads, primarily catering to customers who drive, or, as for drive-through windows, exclusively cater to drivers. In that case, neighborhood food environments may not be as strongly associated with dietary intake or obesity. This could also apply to other types of outlets that cater to drivers, such as large supermarkets. Indeed, several recent studies have not replicated initial claims that supermarkets prevent obesity or that fast-food restaurants exacerbate it and instead find no association or have heavily qualified results, including specific analyses for California.(An \& Sturm, 2012; Boone-Heinonen, et al., 2011; Hattori, et al., 2013; Shier, et al., 2012) The CARDIA longitudinal analysis found an association of fast-food restaurants with fast-food consumption only among low-income men.(BooneHeinonen, et al., 2011) The absence of a substantively important link between diet and nearby outlets at the population level may be a reflection of a mobile society. A UK study observed the strongest and most significant environmental associations when adding commuting routes and work location, which is consistent with the notion that behaviors are best understood in the context of activity spaces. (Burgoine, et al., 2014)

\section{CONCLUSIONS}

The Los Angeles Fast-Food Ban has been a unique policy effort aimed at altering diet behavior and preventing obesity by changing food environments. However, we find no evidence that it resulted in improving the diet of residents or reduce obesity rates. This can be due to study and data limitation, but substantive reasons suggest a slow change in the food environment, failure of the regulation targeting the key differences in food environments, and possibly a limited association between neighborhood food outlets and diet.

\section{Acknowledgments}

This project was supported by grant no. 1R03CA173040-01 from the National Cancer Institute.

\section{References}

An R, Sturm R. School and residential neighborhood food environment and diet among california youth. [Electronic version]. American Journal of Preventive Medicine. 2012; 42(2):129-135. [PubMed: 22261208]

Boone-Heinonen J, Gordon-Larsen P, Kiefe CI, Shikany JM, Lewis CE, Popkin BM. Fast food restaurants and food stores: Longitudinal associations with diet in young to middle-aged adults: The CARDIA study. [Electronic version]. Archives of Internal Medicine. 2011; 171(13):1162-1170. [PubMed: 21747011]

Burgoine T, Forouhi NG, Griffin SJ, Wareham NJ, Monsivais P. Associations between exposure to takeaway food outlets, takeaway food consumption, and body weight in cambridgeshire, UK: Population based, cross sectional study. [Electronic version]. BMJ: British Medical Journal. 2014:348.

City of Los Angeles. The official website of the city of los angeles. Retrieved 3/19, 2014 from http:// www.lacity.org/index.htm

Community Health Councils. News release. community opposes lifting restrictions on fast food development. 2013. Retrieved 8/28, 2014 from http://www.chc-inc.org/downloads/PR $\%$ 202013-04-11\%20CPC\%20Hearing.pdf 
County of Los Angeles. Department of public health. Retrieved 6/26, 2014 from http:// www.publichealth.lacounty.gov/

Gorber SC, Tremblay MS. The bias in self-reported obesity from 1976 to 2005: A canada-US comparison. [Electronic version]. Obesity. 2009; 18(2):354-361. [PubMed: 19556977]

Hattori A, An R, Sturm R. Neighborhood food outlets, diet, and obesity among california adults, 2007 and 2009. [Electronic version]. Prev Chronic Dis. 2013; 10:120123.

Larson NI, Story MT, Nelson MC. Neighborhood environments: Disparities in access to healthy foods in the U.S. [Electronic version]. American Journal of Preventive Medicine. 2009; 36(1):74-81. [PubMed: 18977112]

Liese AD, Barnes TL, Lamichhane AP, Hibbert JD, Colabianchi N, Lawson AB. Characterizing the food retail environment: Impact of count, type, and geospatial error in 2 secondary data sources. [Electronic version]. Journal of Nutrition Education and Behavior. 2013; 45(5):435-442. [PubMed: 23582231]

Liese AD, Colabianchi N, Lamichhane AP, Barnes TL, Hibbert JD, Porter DE, et al. Validation of 3 food outlet databases: Completeness and geospatial accuracy in rural and urban food environments. [Electronic version]. American Journal of Epidemiology. 2010; 172(11):13241333. [PubMed: 20961970]

Merrill RM, Richardson JS. Validity of self-reported height, weight, and body mass index: Findings from the national health and nutrition examination survey, 2001-2006. Prev Chronic Dis. 2009; 6(4):A121. [PubMed: 19754997]

Office of the City Clerk, City of Los Angeles. Council file no. 10-1843. 2010.

Council File no. 07-1658. Fast Food restaurants/interim Control ordinance/West-Adams-BaldwinhillsLeimert, South and Southeast Los Angeles, 2008). from http://cityclerk.lacity.org/ lacityclerkconnect/index.cfm?fa=ccfi.viewrecord\&cfnumber=07-1658

Powell LM, Han E, Zenk SN, Khan T, Quinn CM, Gibbs KP, et al. Field validation of secondary commercial data sources on the retail food outlet environment in the U.S. [Electronic version]. Health \& Place. 2011; 17(5):1122-1131. [PubMed: 21741875]

Shier V, An R, Sturm R. Is there a robust relationship between neighbourhood food environment and childhood obesity in the USA? [Electronic version]. Public Health. 2012; 126(9):723-730. [PubMed: 22898435]

Stommel M, Schoenborn C. Accuracy and usefulness of BMI measures based on self-reported weight and height: Findings from the NHANES \& NHIS 2001-2006. [Electronic version]. BMC Public Health. 2009; 9(1):421. [PubMed: 19922675]

Sturm R, Cohen DA. Zoning for health? the year-old ban on new fast-food restaurants in south LA. [Electronic version]. Health Affairs. 2009; 28(6):w1088-w1097. [PubMed: 19808703]

UCLA Center for Health Policy Research. CHIS california health interview survey. Retrieved 3/19, 2014 from http://www.chis.ucla.edu/

White House Task Force on Childhood Obesity. Solving the problem of childhood obesity within a generation - white house task force on childhood obesity report to the president. Washington, D.C: 2010. Retrieved 2/20/2012, from www.letsmove.gov/white-house-task-force-childhood-obesityreportpresident

World Health Organization. Health topics. obesity. Retrieved 3/19, 2014 from http://www.who.int/ topics/obesity/en/

Wu HW, Sturm R. What's on the menu? A review of the energy and nutritional content of US chain restaurant menus. [Electronic version]. Public Health Nutrition. 2013; 16(01):87-96. [PubMed: 22575557] 


\section{Research highlights}

- Examine empirically the public health implications of "Los Angeles Fast Food Ban"

- Assess differences in food environments across areas within Los Angeles county

- Assess changes in diet and weight status between pre and post the regulation

- Discuss reasons of null finding from theoretical and methodological standpoints 


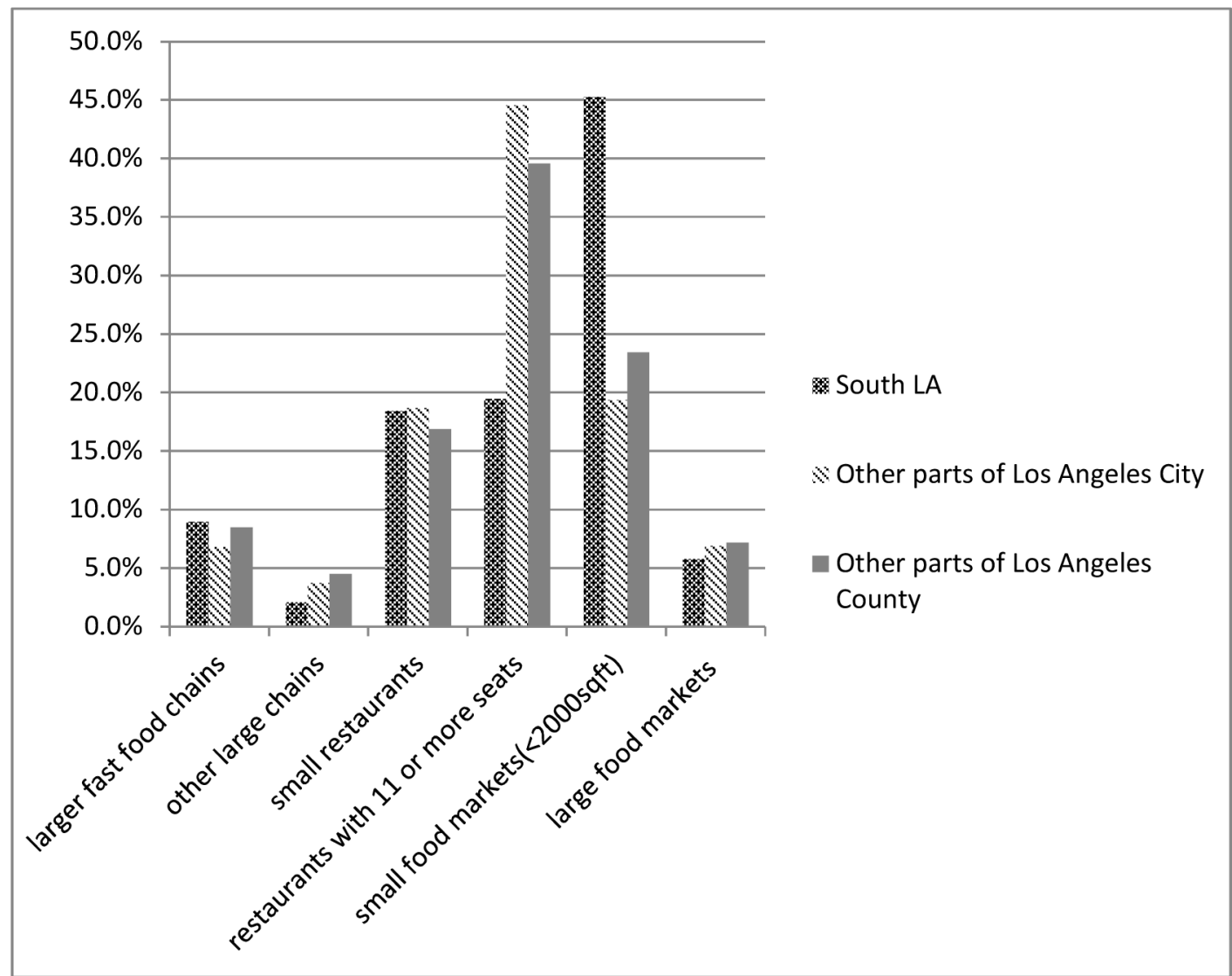

Figure 1.

Percentages of permit/license issued after the regulation to different types of food retail outlets in South Los Angeles, other parts of Los Angeles City, and other parts of Los Angeles County ${ }^{\mathrm{a}}$

Source: Authors' analysis of the permit/license database of food retail outlets obtained from the Los Angeles County Department of Public Health.

${ }^{a}$ the percentage represents the share of permit/license by types of food retail outlets among all types of food retail outlet permits/licenses issued on/after September 14, 2008 in each of the three areas of South Los Angeles, other parts of Los Angeles City, and other parts of Los Angeles County. 


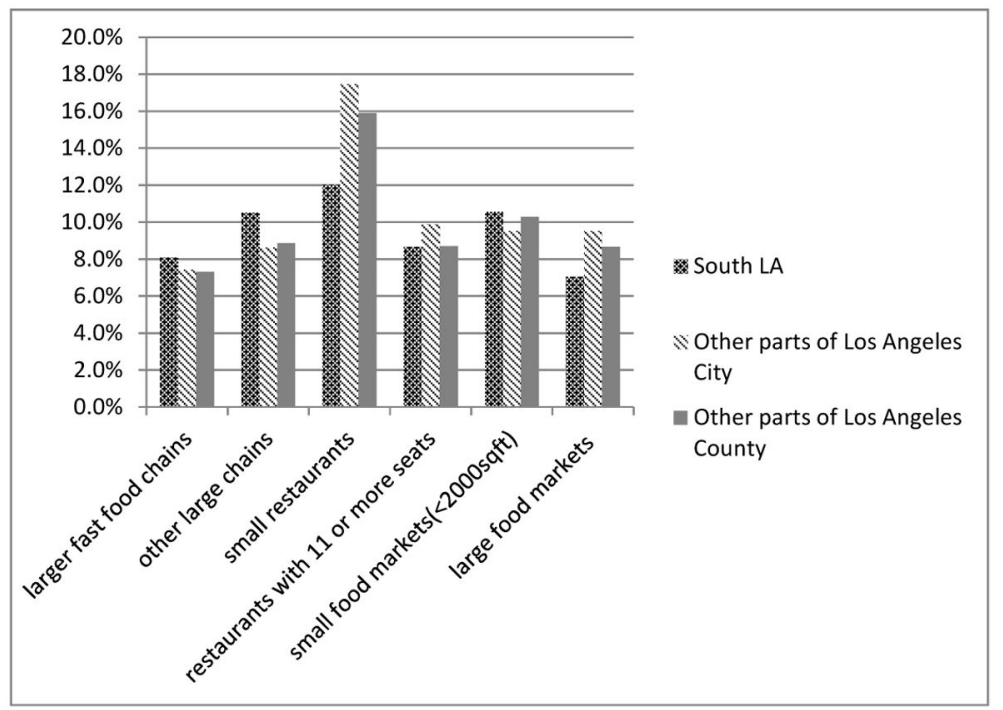

Figure 2.

Percentages of permit/license issued after the regulation among active food retail outlets by types in South Los Angeles

Source: Authors' analysis of the permit/license database of food retail outlets obtained from the Los Angeles County Department of Public Health.

athe percentage represents the share of permit/license by types of food retail outlets among existing food retail outlets as of February 2013 in each of the three areas of South Los Angeles, other parts of Los Angeles City, and other parts of Los Angeles County. 


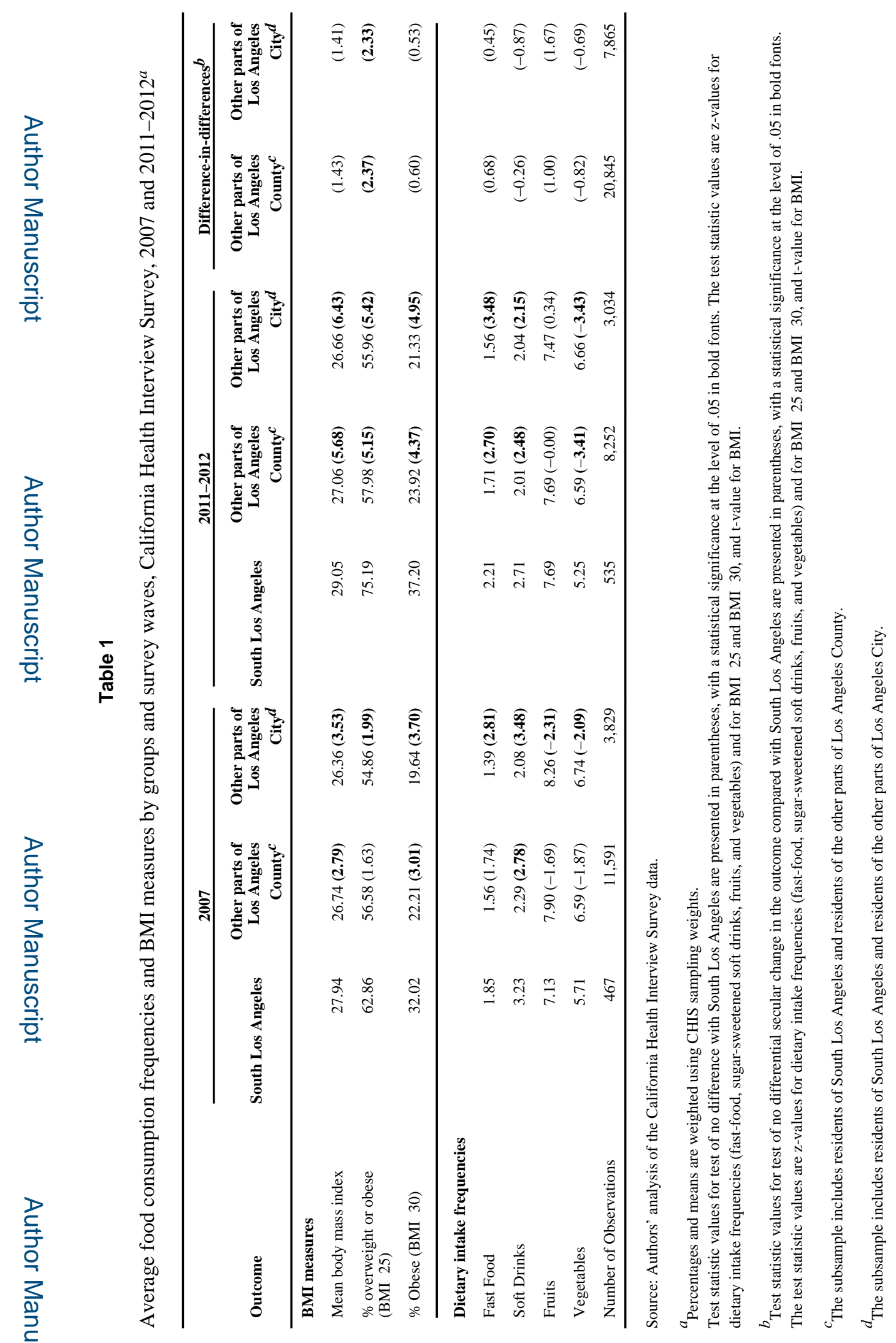

Soc Sci Med. Author manuscript; available in PMC 2016 May 01. 


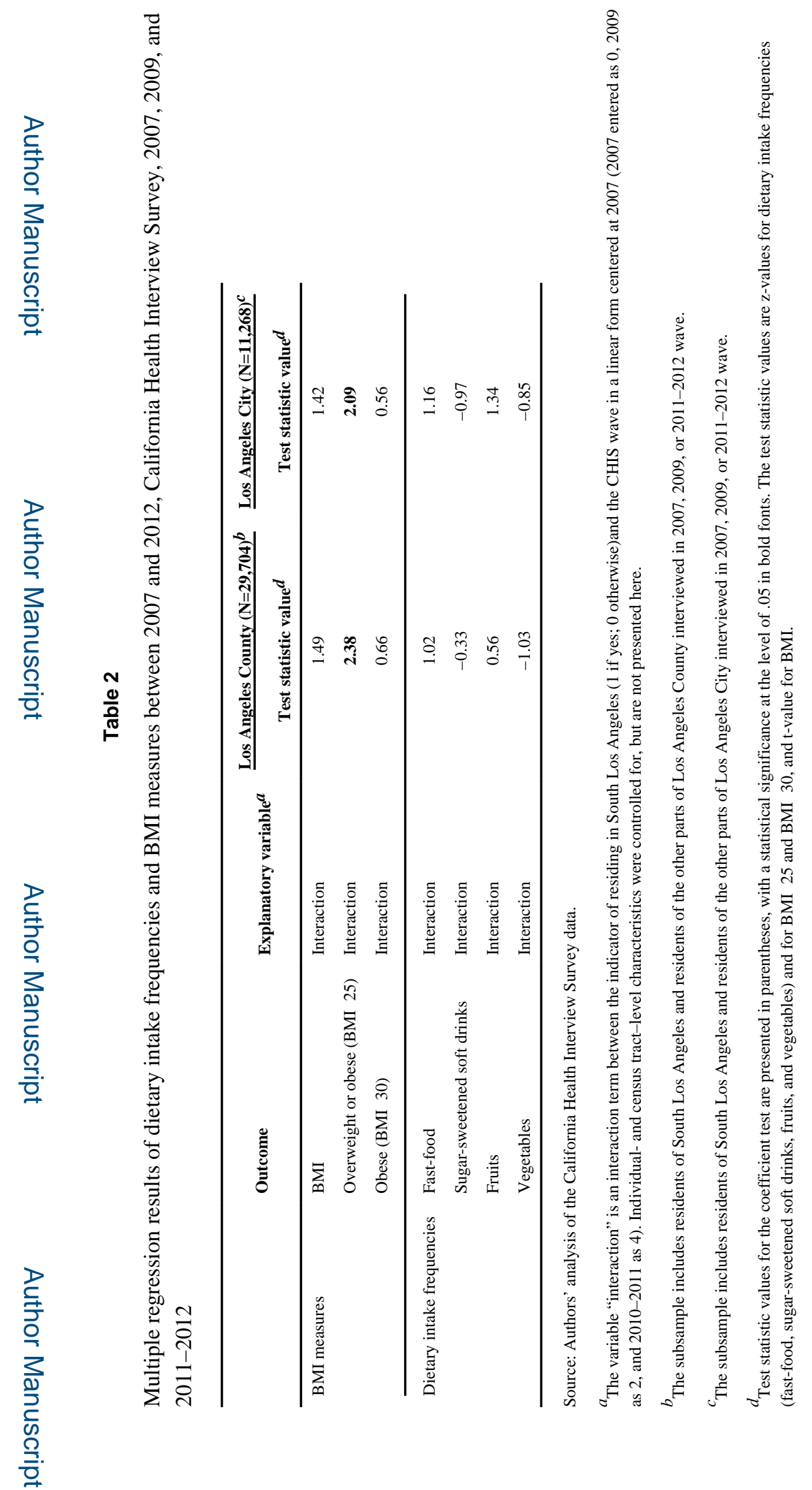

Soc Sci Med. Author manuscript; available in PMC 2016 May 01. 